\title{
Evaluation of antidiabetic activity of herbal tablet containing three indigenous herbs of Assam
}

Mr. Md. Ashaduz Zaman ${ }^{1 *}$, Dr. H.K. Sharma ${ }^{2}$

${ }^{1} \mathrm{Ph} . D$. Research Scholar, College of Pharmacy, Sri Satya Sai University of Technology \& Medical Sciences, Sehore, M.P.-466001, India ${ }^{2}$ Dean, College of Pharmacy, Sri Satya Sai University of Technology \& Medical Sciences, Sehore, M.P.-466001, India

\author{
DOI: $10.36348 /$ simps.2020.v06i09.007 \\ | Received: 07.08.2020 | Accepted: 14.09.2020 | Published: 30.09.2020 \\ *Corresponding author: Mr. Md. Ashaduz Zaman \\ Email: ashad.pharma@gmail.com
}

\section{Abstract}

Objective: The present study is aimed to evaluate an antidiabetic herbal tablet containing Oryza sativa L. var Joha Rice, Dillenia indica and Syzygium cumini Lam. of Assam. Material \& Methods: The plants materials were obtained from local area and authenticated by botanist and extracted using solvent ethanol using soxlet apparatus. The poly herbal tablet is prepared using plant extracts with excipients by granulation method. The anti diabetic study of the herbal tablets were done in streptozotocin induced diabetic rats. Results: In our study we found that best two herbal tablet formulations in doses $(250 \mathrm{mg} / \mathrm{kg}, 500 \mathrm{mg} / \mathrm{kg})$ significantly lowered the fasting blood glucose levels in rats compared to control group. Moreover, the effect continued to sustain after withdrawal of drug treatment. Similarly, these tablet formulations found to improve lipid profiles (TG, HDL, LDS, VLDL, TC) and serum creatinine level and body weight. Conclusion: It can be concluded that the prepared formulation of poly herbal antidiabetic tablets showed very good antidiabetic activity in animal studies. By further, clinical studies, we can prepare a cost effective herbal formulation for diabetes.

Keywords: Oryza sativa L. var Joha Rice, Dillenia indica, Syzygium cumini, Antidiabetic study, streptozotocin, fasting blood glucose.

\footnotetext{
Copyright @ 2020: This is an open-access article distributed under the terms of the Creative Commons Attribution license which permits unrestricted use, distribution, and reproduction in any medium for non-commercial use (NonCommercial, or CC-BY-NC) provided the original author and source are credited.
}

\section{INTRODUCTION}

Assam, a state in North-East India is one of the rich biodiversity zones of India. It is inhabitant of thousands of natural herbs and medicinal plants. Due to unique geographical location, high rainfall, fertile soil and friendly climate favour Assam for tremendous herbal resources. As per government report, there are more than three thousand medicinal plants have been identified in Assam but a few numbers of plants are currently utilized and globally recognized like tea(Chimellia assamica), sarpogandha(Roulfia serpentina), Umlakhi (Amlica officinalis) etc. [1]. Due to lack of knowledge, inadequate facilities, lack of interest, insufficient research make it difficult to explore the herbal gift of Assam.

Diabetes mellitus is one of the leading metabolic diseases affecting almost $50 \%$ of elderly population and a cause of death. As per WHO reports, 422 million peoples suffering from diabetics globally in 2014 and in 2012 diabetes was the direct cause of 1.5 million deaths and high blood glucose was the cause of another 2.2 million deaths [2]. According to the International Diabetes Foundation, India has more number of diabetes patients than any other country in the world [3]. Diabetes currently affects more than 62 million Indians, which is more than $7.1 \%$ of the adult population, and nearly 1 million Indians die due to diabetes every year. According to the Indian Heart Association, India is projected to be home to 109 million individuals with diabetes by 2035 [4].

Studies in India estimate that, for a low income Indian family spend with a diabetic patient spend more than $20 \%$ of family income in the treatment of diabetics on average monthly between 3000 to 8000 INR. Diabetes for five years would have spent around Rs $1,50,000$ on diabetes treatment only. After 10 years one would have spent Rs 4,00,000 and after 20 years one would have spent Rs 15,00,000. The increase in cost with time is due to the increase in complications. The costs of diabetes affect everyone, everywhere, and are a major financial problem. India is a poor country in which $92 \%$ populations having income less than 10000 INR per month and even nearly 75 percent of them survive on a monthly income of less than Rs 5,000[5, 6]. In this scenario, it is very difficult to do the treatment of diabetics for poor Indians. Due to high cost 
of modern medicines it is difficult to bear the cost for common poor people.

The present study is aimed to evaluate antidiabetic activity of formulated herbal tablet containing (Oryza sativa L. belongs to the family Poaccae, Dillenia indica belongs to the family Dilleniaceae and Syzygium cumini var. or Ugenia caryophyllifolia (Lam.) belongs to the family Myrtaceae ) of Assam. The herbal tablets were prepared and evaluated and reported in our previous publication [7].

\section{Materials ANd Methods}

\section{Collection of Plant Material}

The plant materials, Viz., Oryza sativa L Var. Joha Rice, Dillenia indica L fruit and Syzygium cumini (L.) fruit seeds were collected from Local Village of Nagaon District of Assam in the months of December and January 2016.

\section{Authentication of Plant Materials}

The plant materials, Viz., Oryza sativa L Var. Joha Rice, Dillenia indica L fruit and Syzygium cumini
(L.) Seed were authenticated by Taxonomist Dr. Farishta Yasmin, HOD and Associate Professor, Department of Botany, Nowgong College, Nagaon, Assam with Ref. No. NC/BOT/2016/50 dated on 15.02.2017

\section{Extraction of Plant Materials}

Oryza sativa L Var. Joha Rice (Seed), Dillenia indica L fruit and Syzygium cumini (L.) Seed were coarsely powered with dry grinder and passed through sieve and extracted with ethanol in soxlet apparatus

\section{Preparation of Herbal Tablet}

All the individual herbal extracts weighed as per the quantity required on the digital balance and excipients were added and compressed into tablets in Single Rotary Tablet Press. After that tablets were tested for the physical properties like Weight variation, friability, tablets thickness, tablets hardness, and disintegration time and performed antioxidant studies. The best formulations were taken for in-vivo antidiabetic study.

Table-1: Composition of Various formulations with herbal extract

\begin{tabular}{|c|c|c|c|c|c|c|}
\hline \multirow[t]{2}{*}{ Ingredients } & \multicolumn{6}{|c|}{ Quantity per tablet (mg) } \\
\hline & F1 & F2 & F3 & $\mathrm{F} 4$ & F5 & F6 \\
\hline Oryza sativa L Var. Joha Rice Seed extract & 100 & 100 & 100 & 100 & 100 & 100 \\
\hline Dillenia indica $\mathrm{L}$. fruit Extract & 100 & 100 & 100 & 100 & 100 & 100 \\
\hline Syzygium cumini (L.) seed extract & 100 & 100 & 100 & 100 & 100 & 100 \\
\hline Carbopol & 20 & 30 & 40 & - & - & - \\
\hline Ethyl Cellulose & - & - & - & 20 & 30 & 40 \\
\hline Microcrystalline Cellulose & 40 & 40 & 40 & 40 & 40 & 40 \\
\hline Dibasic Calcium Phosphate & 30 & 20 & 10 & 30 & 20 & 10 \\
\hline PEG 4000 & 10 & 10 & 10 & 10 & 10 & 10 \\
\hline Methyl Paraben & $0.1 \%$ & $0.1 \%$ & $0.1 \%$ & $0.1 \%$ & $0.1 \%$ & $0.1 \%$ \\
\hline Weight per tablet & 400 & 400 & 400 & 400 & 400 & 400 \\
\hline
\end{tabular}

\section{Experimental Animals}

Wistar Albino Rats (weight 150-200g body weight) of body weight were used in experiment. This study was conducted according to the guidelines approved by the Institutional Animal Ethics Committee. IAEC permission was taken as per CPCSEA guideline. IAEC of School of Pharmacy, Sri Satya Sai University of Technology \& Medical Sciences is approved by CPCSEA (Reg. No. 1967/PO/Re/S/17/CPCSEA).

\section{Vehicles and Preparation of Doses}

To prepare the dosage forms tablet formulations were made a suspension with $1 \%$ Tween 80. The dose in required concentration was administered at $1 \mathrm{ml} / 100 \mathrm{~g}$ body weight of the animal.

\section{Acute Oral Toxicity Study}

The acute oral toxicity procedure was followed by using OECD 423 guidelines (Guideline OECD, 2001) taking starting dose formulations were
$2000 \mathrm{mg} / \mathrm{kg}$ body weight p.o. and found be under the category of class-VI or Unclassified, $\mathrm{LD}_{50}$ was calculated and $\mathrm{LD}_{50}$ is 5000 . $\mathrm{ED}_{\text {low }}=1 / 20 * 5000=250$ and $\mathrm{ED}_{\text {high }}=1 / 10 * 5000=500$

\section{Evaluation of antidiabetic Activity}

The anti-diabetic activity was studied in rats using streptozocin induced diabetic methods [8-11].

Induction of experimental diabetes:

- Rats, overnight fasted, were injected with single intraperitoneal injection of freshly prepared streptozotocin solution $(60 \mathrm{mg} / \mathrm{kg}$, i.p; dissolved in $0.1 \mathrm{M}$ cold citrate buffer; $\mathrm{pH}$ $4.5)$ to induce experimental type 1diabetes.

- $\quad$ For the i.p. injection of STZ, the rat was held in one hand in dorsal position, the injection site was swabbed using povidone- iodine solution and the designated amount of STZ 
was injected in the caudal abdominal cavity using sterile $25 \mathrm{~g}$ needle.

- $\quad$ STZ induce fatal hypoglycaemia as a result of massive pancreatic insulin release, the rats were provided with $5 \%$ dextrose (glucose) solution after $6 \mathrm{~h}$ of STZ administration for next $24 \mathrm{~h}$ to prevent drug induced hypoglycaemia.

- Streptozotocin induces diabetes within 3 days by destroying the beta cells.

- Diabetes was confirmed at 72 h, after induction of diabetes by polydipsia and polyuria along with measuring the non-fasting plasma glucose.

- Animals, which did not develop more than 200 $\mathrm{mg} / \mathrm{dl}$ glucose levels, were rejected.

- The animal were divided into the following groups and the treatments are given upto $17^{\text {th }}$ day of treatment. After $17^{\text {th }}$ day, we have withdrawn the treatment and animals were given normal feed. Again on $25^{\text {th }}$ day, the withdrawal effect was studied by estimating the biochemical parameters.
i. $\quad$ Normal (Vehicle1\% Tween 80,p.o)
ii. Control (Streptozotocin $60 \mathrm{mg} / \mathrm{kg}$, i.p) + Vehicle1\% Tween 80,p.o)
iii. (Streptozotocin $60 \mathrm{mg} / \mathrm{kg}$, i.p) $+\mathrm{F} 3$ ( $250 \mathrm{mg} / \mathrm{kg}$ in $1 \%$ Tween 80 , p.o)
iv. (Streptozotocin $60 \mathrm{mg} / \mathrm{kg}$, i.p) $+\mathrm{F} 3$ (500mg/kg in $1 \%$ Tween 80 , p.o)
v. (Streptozotocin $60 \mathrm{mg} / \mathrm{kg}$, i.p) $+\mathrm{F} 5$ (250mg/kg in $1 \%$ Tween 80,p.o)
vi. (Streptozotocin $60 \mathrm{mg} / \mathrm{kg}$, i.p) $+\mathrm{F} 5$ (500mg/kg in $1 \%$ Tween 80,p.o)
vii. (Streptozotocin $60 \mathrm{mg} / \mathrm{kg}$, i.p) +Glipizide $(5 \mathrm{mg} / \mathrm{kg}$ in $1 \%$ Tween 80, p.o)

Since diabetic animals drink large amount of fluid and produce large volume of urine, the bedding is changed frequently, usually every day and, in some circumstances, more than once per day. Diabetic rats should have sufficient food and water; therefore only three diabetic rats have been housed per cage to avoid competition for feed and water.

\section{Collection of Serum Samples}

The blood was drawn from the retro orbital plexus of the rats (fasted for $14 \mathrm{~h}$ ) under light ether anaesthesia on different occasions i.e., day 0 , day 1 , day
3 , day 10, day 17 and day 25 . The blood samples were allowed to clot for $30 \mathrm{~min}$ at room temperature and then they were centrifuged at $5000 \mathrm{rpm}$ for $20 \mathrm{~min}$. The resulting upper serum layer was collected in properly labelled, clean and dry micro-centrifuge tubes. The blood samples were stored at $2-8{ }^{\circ} \mathrm{C}$ and analyzed within one week. This serum specimen was used for the estimation of different biochemical parameters.

\section{Estimation of Biochemical Parameters}

Body weight, Fasting Blood glucose level, Triglycerides, Total cholesterol, HDL-cholesterol, LDL-cholesterol, VLDL-cholesterol, Serum Creatinine levels estimated from the serum by using standard kits.

\section{Statistical Analysis}

The data were analyzed by linear regression analyses using Microsoft Office Excel 2010, Graph pad Prism software version-5 by one way analysis of variance (ANOVA).

\section{RESULTS AND DISCUSSION}

In our study, we have used streptozotocin induced diabetic in rats model to study the antidiabetic study of prepared Tablet formulations containing Oryza sativa L Var. Joha Rice (Seed) Extract, Dillenia indica L. fruits Extract and Syzygium cumini (L.) Seed extract. Streptotozocin decreases the insulin secretion by destroying the $\beta$-cells of islets of langerhans in pancreas [12].

Due to this insulin deficiency, diabetes mellitus occurred. Glipizide is used as the standard drug which shows the antidiabetic activity by preventing the destruction of $\beta$-cells and enhancing the secretion of insulin[13].

In our study we found that best two herbal tablet formulations in doses $(250 \mathrm{mg} / \mathrm{kg}, 500 \mathrm{mg} / \mathrm{kg}$ ) significantly lowered the fasting on blood glucose levels in rats compared to control group. Moreover, the effect continued to sustain after withdrawal of drug treatment. Similarly, these tablet formulations found to improve lipid profiles (TG, HDL, LDS, VLDL, TC) and serum creatinine level and body weight. All the results are given below in tables (Table-1 to Table-8) and presented in Figures (Figure-1 to Figure-8). 
Table-1: Effect of herbal tablet formulations on fasting on blood glucose levels in streptozotocin induced diabetic rats

\begin{tabular}{|c|c|c|c|c|c|c|}
\hline \multirow[t]{2}{*}{ Groups } & \multirow[t]{2}{*}{ Treatment } & \multicolumn{5}{|c|}{ Fasting Blood glucose Levels(mg/dl) MEAN \pm SEM } \\
\hline & & 0 Day & $3^{\text {rd }}$ Day & ${ }^{10^{\text {th }}}$ Day & $17^{\text {th }}$ Day & $25^{\text {th }}$ Day \\
\hline $\mathrm{I}$ & $\begin{array}{l}\text { Normal (Vehicle1\% Tween } \\
\text { 80,p.o) }\end{array}$ & $93.34 \pm 2.33$ & $92.64 \pm 3.56$ & $89.67 \pm 4.50$ & $90.57 \pm 2.05$ & $92.30 \pm 3.50$ \\
\hline II & $\begin{array}{l}\text { Control (Streptozotocin } 60 \\
\text { mg/kg, i.p) + Vehicle1\% } \\
\text { Tween 80,p.o) }\end{array}$ & $95.12 \pm 2.40^{\text {ans }}$ & $520.50 \pm 13.12^{\mathrm{a}^{* * * *}}$ & $\begin{array}{l}523.60 \pm 15.34 \\
\mathrm{a}^{* * * *}\end{array}$ & $\begin{array}{l}465.20 \pm 10.22 \\
\mathrm{a}^{* * * *}\end{array}$ & $446.50 \pm 10.52^{\mathrm{a}^{* * *}}$ \\
\hline III & $\begin{array}{l}\text { (Streptozotocin } 60 \mathrm{mg} / \mathrm{kg} \text {, i.p) } \\
+ \text { F3 }(250 \mathrm{mg} / \mathrm{kg} \text { in } 1 \% \text { Tween } \\
\text { 80,p.o) }\end{array}$ & $92.64 \pm 2.42^{\text {bns }}$ & $498.42 \pm 11.45^{\text {bns }}$ & $\underset{\substack{\mathrm{b}^{* * *} \\
360.44 \pm 12.20}}{ }$ & $173.50 \pm 7.40^{\mathrm{b}^{* * *}}$ & $146.64 \pm 6.30^{\mathrm{b}^{* * *}}$ \\
\hline IV & $\begin{array}{l}\text { (Streptozotocin } 60 \mathrm{mg} / \mathrm{kg} \text {, i.p) } \\
+ \text { F } 3(500 \mathrm{mg} / \mathrm{kg} \text { in } 1 \% \text { Tween } \\
\text { 80,p.o) }\end{array}$ & $93.76 \pm 3.50^{\text {bns }}$ & $490.53 \pm 11.20^{\mathrm{bns}}$ & $\underset{b^{* * *}}{342.52 \pm 11.32}$ & $153.45 \pm 8.30^{\mathrm{b}^{* * *}}$ & $133.62 \pm 7.45^{\mathrm{b}^{* * *}}$ \\
\hline V & $\begin{array}{l}\text { (Streptozotocin } 60 \mathrm{mg} / \mathrm{kg} \text {, i.p) } \\
\text { +F5 }(250 \mathrm{mg} / \mathrm{kg} \text { in } 1 \% \text { Tween } \\
\text { 80,p.o) }\end{array}$ & $92.78 \pm 2.78^{\text {bns }}$ & $487.56 \pm 12.20^{\mathrm{b}^{*}}$ & $\underset{b * * *}{250.54 \pm 12.30}$ & $165.85 \pm 6.62^{b^{* * *}}$ & $153.50 \pm 6.55^{b^{* * * *}}$ \\
\hline VI & $\begin{array}{l}\text { (Streptozotocin } 60 \mathrm{mg} / \mathrm{kg} \text {, i.p) } \\
\text { +F5 }(500 \mathrm{mg} / \mathrm{kg} \text { in } 1 \% \text { Tween } \\
\text { 80,p.o) }\end{array}$ & $90.76 \pm 4.30^{\text {bns }}$ & $487.65 \pm 8.30^{\mathrm{b}^{* * * *}}$ & $\underset{\mathrm{b}^{* * *}}{236.32 \pm 11.61}$ & $144.13 \pm 6.82^{b^{* * *}}$ & $156.27 \pm 5.78^{b^{* * *}}$ \\
\hline VII & $\begin{array}{l}\text { (Streptozotocin } 60 \mathrm{mg} / \mathrm{kg} \text {, i.p) } \\
\text { +Glipizide }(5 \mathrm{mg} / \mathrm{kg} \text { in } 1 \% \\
\text { Tween 80,p.o) }\end{array}$ & $93.40 \pm 2.52^{\text {bns }}$ & $485.34 \pm 7.60^{\mathrm{bns}}$ & $223.30 \pm 8.67^{\mathrm{b} * * *}$ & $122.64 \pm 7.60^{\mathrm{b}^{* * *}}$ & $154.42 \pm 5.30^{\mathrm{b}^{* * *}}$ \\
\hline
\end{tabular}

Values are in Mean \pm S.E.M $(n=6),{ }^{\text {ns }}$-Non Significant, ${ }^{*} \mathbf{p}<0.05, * * p<0.01, * * * p<0.001{ }^{\text {a }}$ Control compared with Normal, ${ }^{b}$ All test groups compared with Control using One way ANOVA followed by Dunnet's “ $t$ " test.

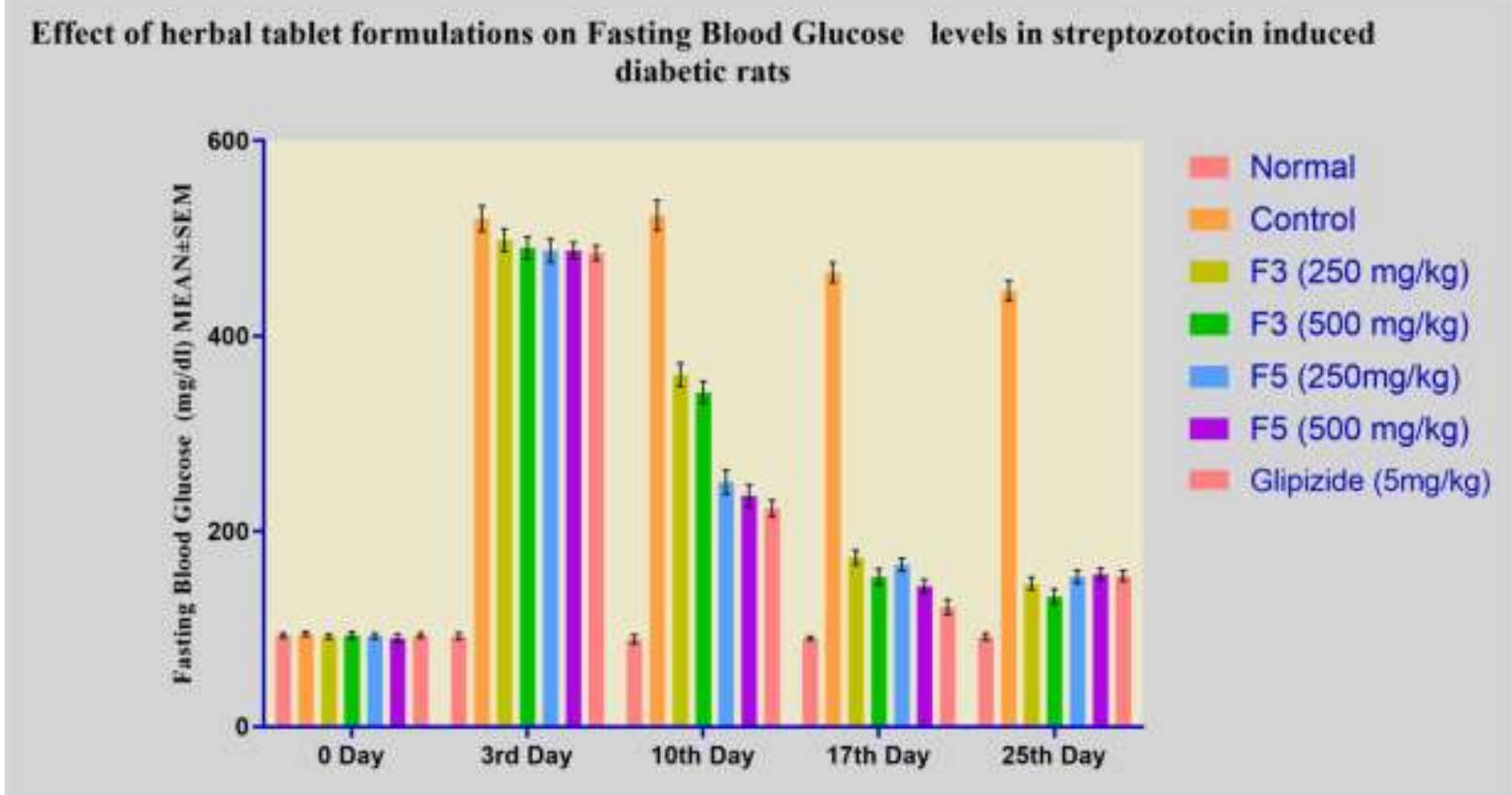

Figure-1: Effect of herbal tablet formulations on fasting on blood glucose levels in streptozotocin induced diabetic rats 
Table-2: Effect of herbal tablet formulations on Triglycerides levels in streptozotocin induced diabetic rats

\begin{tabular}{|c|c|c|c|c|c|c|}
\hline \multirow{2}{*}{ Groups } & \multirow{2}{*}{ Treatment } & \multicolumn{5}{|c|}{ Triglycerides (mg/dl) MEAN \pm SEM } \\
\hline & & 0 Day & $3^{\text {rd }}$ Day & ${ }^{10 \text { th }}$ Day & $17^{\text {th }}$ Day & $25^{\text {th }}$ Day \\
\hline $\mathrm{I}$ & $\begin{array}{l}\text { Normal (Vehicle1\% Tween } \\
\text { 80,p.o) }\end{array}$ & $90.30 \pm 2.40$ & $91.30 \pm 2.85$ & $90.17 \pm 2.60$ & $90.45 \pm 2.54$ & $88.40 \pm 1.73$ \\
\hline II & $\begin{array}{l}\text { Control (Streptozotocin } 60 \\
\mathrm{mg} / \mathrm{kg}, \text { i.p) + Vehicle1\% } \\
\text { Tween 80,p.o) }\end{array}$ & $91.33 \pm 3.80^{\text {ans }}$ & $200.32 \pm 6.50^{\mathrm{a}^{* * * *}}$ & $212.56 \pm 3.42^{\mathrm{a}^{* * * *}}$ & $197.20 \pm 3.32^{\mathrm{a}^{* * *}}$ & $178.20 \pm 2.40^{\mathrm{a}^{* * * *}}$ \\
\hline III & $\begin{array}{l}\text { (Streptozotocin } 60 \mathrm{mg} / \mathrm{kg} \text {, i.p) } \\
+\mathrm{F} 3(250 \mathrm{mg} / \mathrm{kg} \text { in } 1 \% \text { Tween } \\
\text { 80,p.o) }\end{array}$ & $88.50 \pm 3.44^{\text {bns }}$ & $182.32 \pm 4.57^{\mathrm{bns}}$ & $172.30 \pm 3.32^{\mathrm{b}^{*}}$ & $144.56 \pm 5.52^{\mathrm{b}^{* * * *}}$ & $134.23 \pm 5.35^{\mathrm{b}^{* * * *}}$ \\
\hline IV & $\begin{array}{l}\text { (Streptozotocin } 60 \mathrm{mg} / \mathrm{kg} \text {, i.p) } \\
+ \text { F3 (500mg/kg in } 1 \% \text { Tween } \\
\text { 80,p.o) }\end{array}$ & $89.78 \pm 3.60^{\text {bns }}$ & $165.40 \pm 4.56^{\mathrm{bns}}$ & $152.44 \pm 2.60^{b^{*}}$ & $135.54 \pm 5.22^{\mathrm{b}^{* * * *}}$ & $122.20 \pm 3.28^{\mathrm{b} * * *}$ \\
\hline V & $\begin{array}{l}\text { (Streptozotocin } 60 \mathrm{mg} / \mathrm{kg} \text {, i.p) } \\
+\mathrm{F} 5(250 \mathrm{mg} / \mathrm{kg} \text { in } 1 \% \text { Tween } \\
\text { 80,p.o) }\end{array}$ & $91.55 \pm 3.40^{\text {bns }}$ & $177.40 \pm 6.43^{\mathrm{bns}}$ & $157.56 \pm 2.55^{\mathrm{b}^{*}}$ & $134.34 \pm 3.90^{b^{* * * *}}$ & $124.30 \pm 3.20^{\mathrm{b}^{* * * *}}$ \\
\hline VI & $\begin{array}{l}\text { (Streptozotocin } 60 \mathrm{mg} / \mathrm{kg} \text {, i.p) } \\
+ \text { +F5 }(500 \mathrm{mg} / \mathrm{kg} \text { in } 1 \% \text { Tween } \\
\text { 80,p.o) }\end{array}$ & $90.67 \pm 2.15^{\text {bns }}$ & $157.33 \pm 6.50^{\mathrm{b}^{* * *}}$ & $149.65 \pm 4.65^{\mathrm{b}^{* * *}}$ & $124.50 \pm 3.70$ & $114.10 \pm 3.20^{\mathrm{b} * * *}$ \\
\hline VII & $\begin{array}{l}\text { (Streptozotocin } 60 \mathrm{mg} / \mathrm{kg} \text {, i.p) } \\
\text { +Glipizide }(5 \mathrm{mg} / \mathrm{kg} \text { in } 1 \% \\
\text { Tween } 80, \text { p.o) }\end{array}$ & $90.44 \pm 3.90^{\text {bns }}$ & $194.75 \pm 6.90^{\mathrm{bns}}$ & $175.72 \pm 4.56^{\mathrm{b}^{* * *}}$ & $153.80 \pm 3.17^{\mathrm{b}^{* * *}}$ & $136.30 \pm 3.30^{\mathrm{b}^{* * * *}}$ \\
\hline
\end{tabular}

Values are in Mean \pm S.E.M $(\mathbf{n}=6),{ }^{\mathrm{ns}}$-Non Significant, ${ }^{*} \mathbf{p}<0.05, * * \mathbf{p}<0.01, * * * \mathbf{p}<0.001{ }^{\text {a }}$ Control compared with Normal, ' All test groups compared with Control using One way ANOVA followed by Dunnet's “ $t$ ”" test.

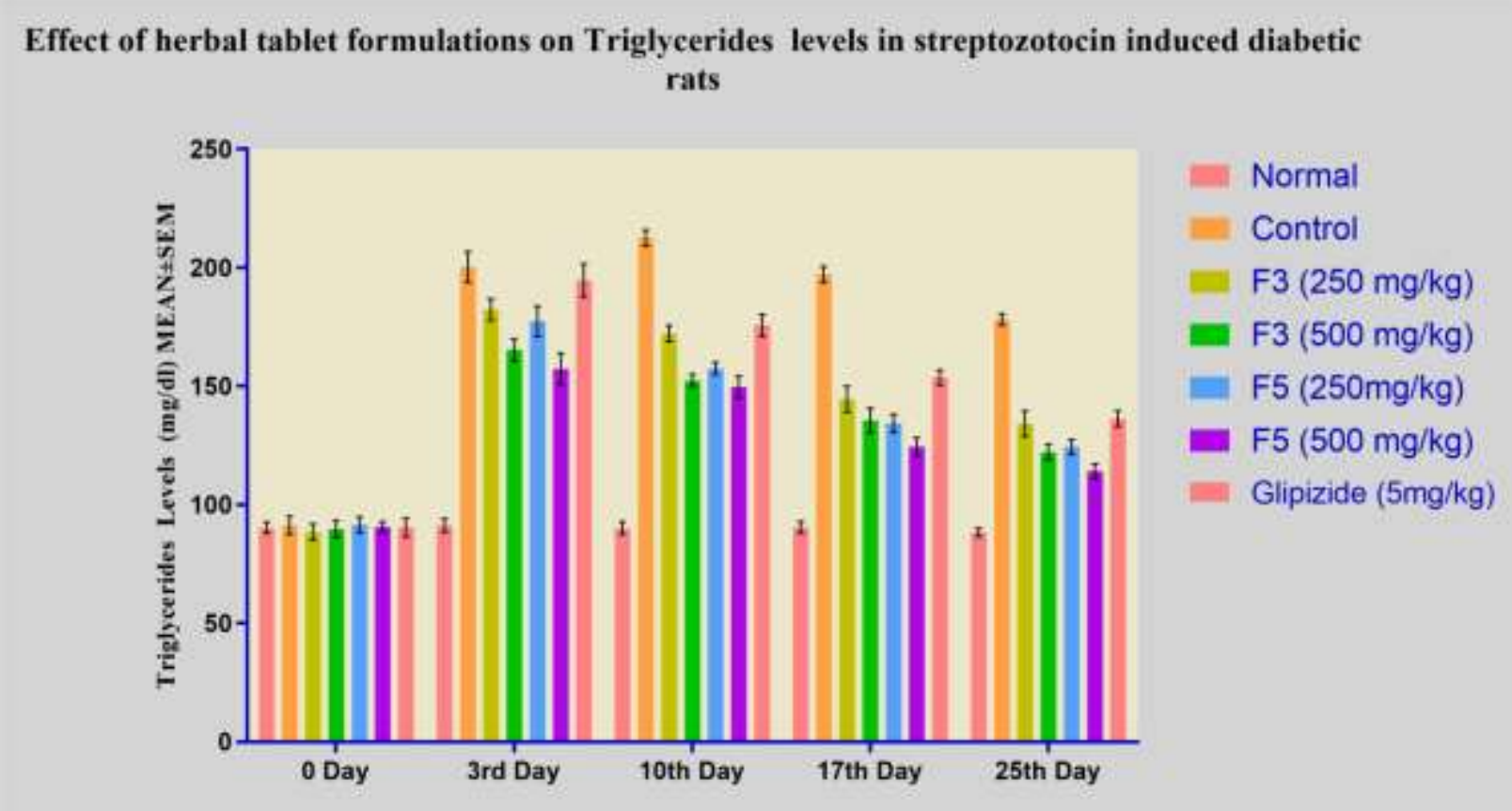

Figure-2: Effect of herbal tablet formulations on Triglycerides levels in streptozotocin induced diabetic rats 
Zaman AM \& Sharma HK; Saudi J Med Pharm Sci, September, 2020; 6(9): 627-638

Table-3: Effect of herbal tablet formulations on HDL levels in streptozotocin induced diabetic rats

\begin{tabular}{|c|c|c|c|c|c|c|}
\hline \multirow{2}{*}{ Groups } & \multirow{2}{*}{ Treatment } & \multicolumn{5}{|c|}{ HDL (mg/dl)MEAN \pm SEM } \\
\hline & & 0 Day & $3^{\text {rd }}$ Day & 10th Day & $17^{\text {th }}$ Day & $25^{\text {th }}$ Day \\
\hline $\mathrm{I}$ & Normal (Vehicle1\% Tween 80,p.o) & $77.40 \pm 2.12$ & $75.30 \pm 2.12$ & $75.60 \pm 2.90$ & $76.14 \pm 2.34$ & $78.20 \pm 2.30$ \\
\hline II & $\begin{array}{l}\text { Control (Streptozotocin } 60 \mathrm{mg} / \mathrm{kg} \text {, i.p) + } \\
\text { Vehicle1\% Tween 80,p.o) }\end{array}$ & $76.80 \pm 2.35^{\text {ans }}$ & $18.83 \pm 1.50^{\mathrm{a}^{* * *}}$ & $29.53 \pm 1.74^{\mathrm{a}^{* * *}}$ & $29.32 \pm 2.32^{\mathrm{a}^{* * *}}$ & $30.80 \pm 1.42^{\mathrm{a}^{* * *}}$ \\
\hline III & $\begin{array}{l}\text { (Streptozotocin } 60 \mathrm{mg} / \mathrm{kg}, \text { i.p) }+\mathrm{F} 3 \\
(250 \mathrm{mg} / \mathrm{kg} \text { in } 1 \% \text { Tween } 80, \mathrm{p} . \mathrm{o})\end{array}$ & $75.46 \pm 2.23^{\text {bns }}$ & $32.30 \pm 1.56^{\mathrm{b}^{* * * *}}$ & $42.25 \pm 1.32^{\mathrm{b}^{* * * *}}$ & $36.60 \pm 2.24^{\mathrm{b}^{* * * *}}$ & $51.10 \pm 2.32^{\mathrm{b}^{* * * *}}$ \\
\hline IV & $\begin{array}{l}\text { (Streptozotocin } 60 \mathrm{mg} / \mathrm{kg}, \text { i.p) }+\mathrm{F} 3 \\
(500 \mathrm{mg} / \mathrm{kg} \text { in } 1 \% \text { Tween } 80, \mathrm{p} . \mathrm{o})\end{array}$ & $77.34 \pm 2.53^{\text {bns }}$ & $36.13 \pm 1.65^{\mathrm{b}^{* * *}}$ & $46.34 \pm 2.53^{\mathrm{b}^{* * *}}$ & $53.33 \pm 2.35^{\mathrm{b}^{* * * *}}$ & $53.22 \pm 2.22^{\mathrm{b}^{* * * *}}$ \\
\hline V & $\begin{array}{l}(\text { Streptozotocin } 60 \mathrm{mg} / \mathrm{kg}, \text { i.p) }+\mathrm{F} 5 \\
(250 \mathrm{mg} / \mathrm{kg} \text { in } 1 \% \text { Tween } 80, \mathrm{p} . \mathrm{o})\end{array}$ & $75.32 \pm 2.50^{\text {bns }}$ & $34.30 \pm 1.78^{b^{* * * *}}$ & $50.38 \pm 2.66^{\mathrm{b} * * *}$ & $50.52 \pm 1.94^{\mathrm{b}^{* * * *}}$ & $52.17 \pm 1.45^{\mathrm{b}^{* * * *}}$ \\
\hline VI & $\begin{array}{l}\text { (Streptozotocin } 60 \mathrm{mg} / \mathrm{kg}, \text { i.p) }+\mathrm{F} 5 \\
(500 \mathrm{mg} / \mathrm{kg} \text { in } 1 \% \text { Tween } 80, \mathrm{p} . \mathrm{o})\end{array}$ & $78.50 \pm 2.83^{\text {bns }}$ & $38.53 \pm 1.60^{\mathrm{b}^{* * *}}$ & $56.60 \pm 1.62^{\mathrm{b}^{* * *}}$ & $58.50 \pm 2.50^{\mathrm{b}^{* * *}}$ & $63.83 \pm 2.45^{\mathrm{b}^{* * * *}}$ \\
\hline & (Streptozotocin 60 mg/kg, i.p) & & & & & \\
\hline VII & $\begin{array}{l}\text { +Glipizide }(5 \mathrm{mg} / \mathrm{kg} \text { in } 1 \% \text { Tween } \\
\text { 80,p.o) }\end{array}$ & $77.50 \pm 2.54^{\text {bns }}$ & $32.17 \pm 2.40^{\mathrm{b}^{* * * *}}$ & $60.42 \pm 1.45^{\mathrm{b}^{* * * *}}$ & $50.30 \pm 1.42^{b^{* * *}}$ & $58.24 \pm 2.30^{\mathrm{b}^{* * *}}$ \\
\hline
\end{tabular}

Values are in Mean \pm S.E.M $(n=6),{ }^{n s}$-Non Significant, $* p<0.05, * * p<0.01, * * * p<0.001{ }^{\text {a }}$ Control compared with Normal, b All test groups compared with Control using One way ANOVA followed by Dunnet's " $t$ " test.

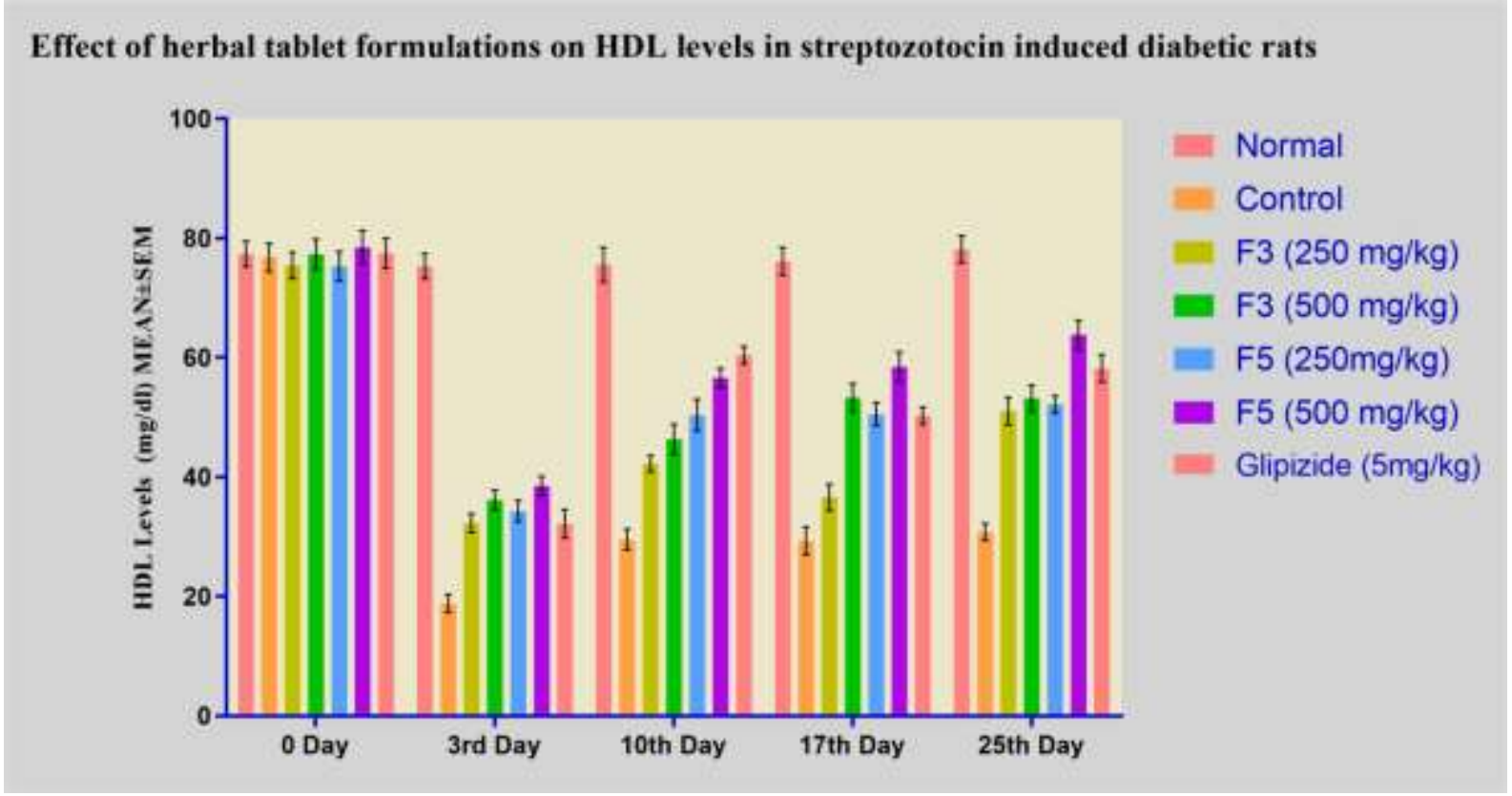

Figure-3: Effect of herbal tablet formulations on HDL levels in streptozotocin induced diabetic rats 
Zaman AM \& Sharma HK; Saudi J Med Pharm Sci, September, 2020; 6(9): 627-638

\begin{tabular}{|c|c|c|c|c|c|c|}
\hline \multirow[t]{2}{*}{ Groups } & \multirow[t]{2}{*}{ Treatment } & \multicolumn{5}{|c|}{ LDL Levels (mg/dl)MEAN \pm SEM } \\
\hline & & 0 Day & $3^{\text {rd }}$ Day & ${ }^{10 \text { th }}$ Day & $17^{\text {th }}$ Day & $25^{\text {th }}$ Day \\
\hline I & Normal (Vehicle1\% Tween 80,p.o) & $29.20 \pm 2.10$ & $26.38 \pm 2.40$ & $25.67 \pm 0.56$ & $28.17 \pm 0.67$ & $29.33 \pm 1.33$ \\
\hline II & $\begin{array}{l}\text { Control (Streptozotocin } 60 \mathrm{mg} / \mathrm{kg} \text {, i.p) } \\
\text { + Vehicle1\% Tween 80,p.o) }\end{array}$ & $28.88 \pm 2.05^{\text {ans }}$ & $95.28 \pm 2.50^{\mathrm{a}^{* * *}}$ & $92.55 \pm 1.53^{\mathrm{a}^{* * * *}}$ & $90.67 \pm 1.11^{\mathrm{a}^{* * *}}$ & $90.42 \pm 1.40^{\mathrm{a}^{* * *}}$ \\
\hline III & $\begin{array}{l}\text { (Streptozotocin } 60 \mathrm{mg} / \mathrm{kg}, \text { i.p })+ \\
\text { F3(250mg/kg in } 1 \% \text { Tween 80,p.o) }\end{array}$ & $29.53 \pm 0.78^{\text {bns }}$ & $77.30 \pm 1.13^{\mathrm{b} * *}$ & $62.42 \pm 1.43^{\mathrm{b}^{* * *}}$ & $48.30 \pm 1.34^{\mathrm{b}^{* * * *}}$ & $42.50 \pm 1.62^{b^{* * *}}$ \\
\hline IV & $\begin{array}{l}\text { (Streptozotocin } 60 \mathrm{mg} / \mathrm{kg} \text {, i.p) }+\mathrm{F} 3 \\
(500 \mathrm{mg} / \mathrm{kg} \text { in } 1 \% \text { Tween } 80, \mathrm{p} . \mathrm{o})\end{array}$ & $28.20 \pm 1.32^{\text {bns }}$ & $75.56 \pm 1.12^{\mathrm{b}^{* * *}}$ & $60.22 \pm 1.52^{\mathrm{b} * * *}$ & $36.50 \pm 1.32^{\mathrm{b} * * *}$ & $36.40 \pm 1.52^{b^{* * *}}$ \\
\hline $\mathrm{V}$ & $\begin{array}{l}(\text { Streptozotocin } 60 \mathrm{mg} / \mathrm{kg}, \text { i.p) }+\mathrm{F5} \\
(250 \mathrm{mg} / \mathrm{kg} \text { in } 1 \% \text { Tween } 80, \text { p.o) }\end{array}$ & $30.27 \pm 1.45^{\text {bns }}$ & $75.56 \pm 2.34^{\mathrm{b} * * *}$ & $57.34 \pm 1.63^{\mathrm{b}^{* * *}}$ & $37.14 \pm 1.10^{\mathrm{b}^{* * *}}$ & $36.30 \pm 0.52^{b^{* * *}}$ \\
\hline VI & $\begin{array}{l}\text { (Streptozotocin } 60 \mathrm{mg} / \mathrm{kg} \text {, i.p) }+\mathrm{F} 5 \\
(500 \mathrm{mg} / \mathrm{kg} \text { in } 1 \% \text { Tween 80,p.o) }\end{array}$ & $29.42 \pm 1.50^{\text {bns }}$ & $70.56 \pm 1.56^{\mathrm{b} * * *}$ & $45.67 \pm 1.82^{b^{* * * *}}$ & $35.82 \pm 1.32^{\mathrm{b}^{* * *}}$ & $30.33 \pm 0.99^{b^{* * *}}$ \\
\hline VII & $\begin{array}{l}\text { (Streptozotocin } 60 \mathrm{mg} / \mathrm{kg} \text {, i.p) } \\
\text { +Glipizide }(5 \mathrm{mg} / \mathrm{kg} \text { in } 1 \% \text { Tween } \\
\text { 80,p.o) }\end{array}$ & $29.55 \pm 1.20^{\text {bns }}$ & $72.34 \pm 1.67^{b^{* * *}}$ & $48.30 \pm 1.52^{\mathrm{b}^{* * *}}$ & $38.82 \pm 1.62^{\mathrm{b}^{* * * *}}$ & $34.67 \pm 1.32^{\mathrm{b}^{* * *}}$ \\
\hline
\end{tabular}

Values are in Mean \pm S.E.M $(n=6),{ }^{\text {ns }}$-Non Significant, ${ }^{*} \mathbf{p}<0.05, * * p<0.01, * * * p<0.001{ }^{\text {a }}$ Control compared with Normal, ${ }^{b}$ All test groups compared with Control using One way ANOVA followed by Dunnet's “ $t$ " test.

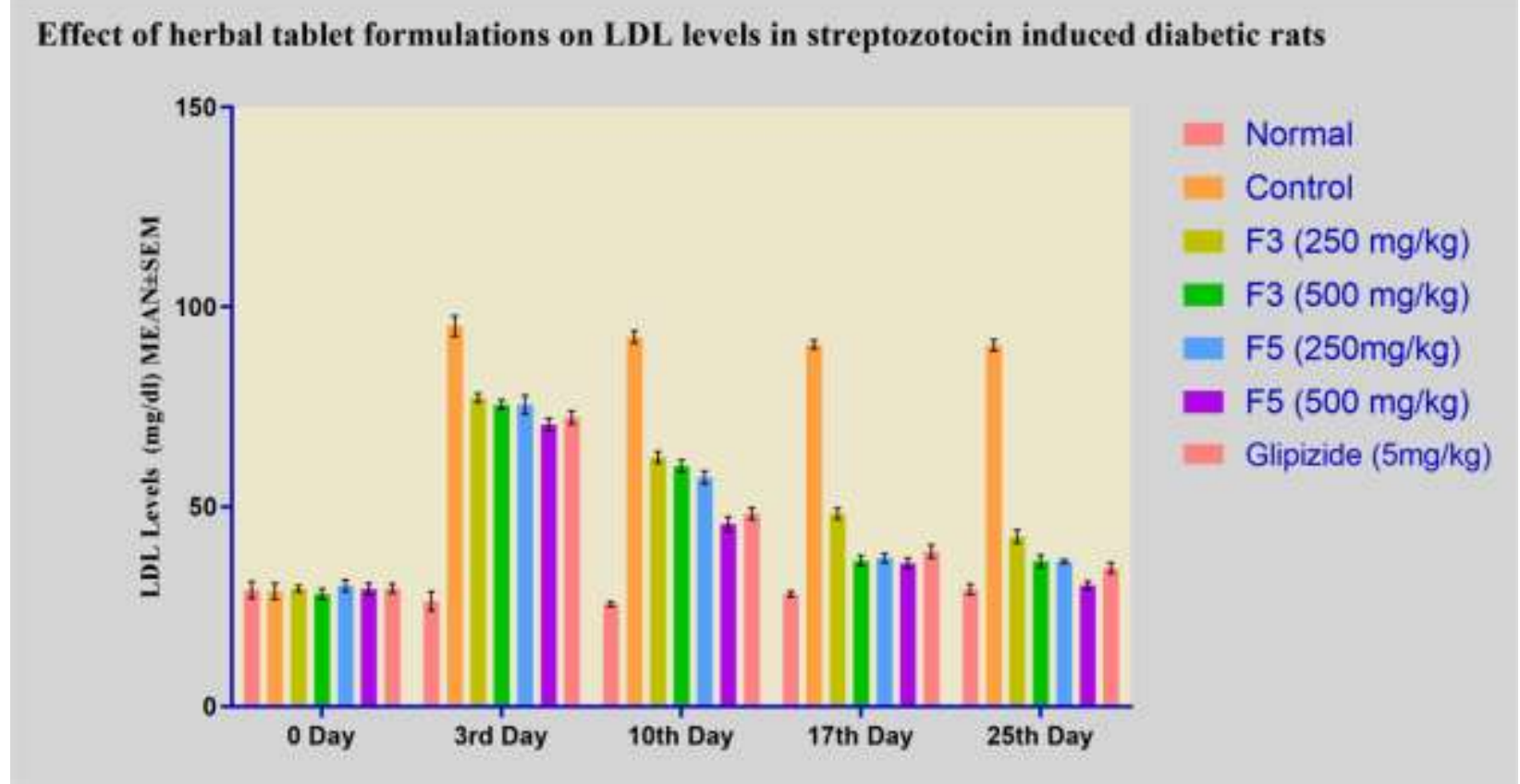

Figure-4: Effect of herbal tablet formulations on LDL levels in streptozotocin induced diabetic rats 
Table-5: Effect of herbal tablet formulations on VLDL levels in streptozotocin induced diabetic rats

\begin{tabular}{|c|c|c|c|c|c|c|}
\hline \multirow[t]{2}{*}{ Groups } & \multirow[t]{2}{*}{ Treatment } & \multicolumn{4}{|c|}{ VLDL Levels (mg/dl) MEAN \pm SEM } & \multirow[b]{2}{*}{$25^{\text {th }}$ Day } \\
\hline & & 0 Day & $3^{\text {rd }}$ Day & 10th Day & $17^{\text {th }}$ Day & \\
\hline $\mathrm{I}$ & Normal (Vehicle1\% Tween 80,p.o) & $20.24 \pm 0.98$ & $19.83 \pm 0.67$ & $20.33 \pm 0.98$ & $20.52 \pm 0.76$ & $21.53 \pm 0.42$ \\
\hline II & $\begin{array}{l}\text { Control (Streptozotocin } 60 \mathrm{mg} / \mathrm{kg}, \mathrm{i} . \mathrm{p})+ \\
\text { Vehicle1\% Tween 80,p.o) }\end{array}$ & $\begin{array}{l}20.30 \pm 0.86 \\
\text { ans }\end{array}$ & $\begin{array}{l}58.50 \pm 1.44 \\
a^{* * * *}\end{array}$ & $57.34 \pm 1.80^{\mathrm{a}^{* * *}}$ & $56.88 \pm 1.56^{\mathrm{a} * * *}$ & $57.32 \pm 1.42^{\mathrm{a***}}$ \\
\hline III & $\begin{array}{l}\text { (Streptozotocin } 60 \mathrm{mg} / \mathrm{kg}, \text { i.p })+\mathrm{F} 3 \\
(250 \mathrm{mg} / \mathrm{kg} \text { in } 1 \% \text { Tween 80,p.o })\end{array}$ & $\begin{array}{l}19.20 \pm 0.65 \\
\text { bns }\end{array}$ & $55.86 \pm 1.52^{\text {bns }}$ & $50.32 \pm 1.45^{\text {bns }}$ & $42.44 \pm 1.34^{b^{*}}$ & $40.22 \pm 0.62^{b^{* *}}$ \\
\hline IV & $\begin{array}{l}\text { (Streptozotocin } 60 \mathrm{mg} / \mathrm{kg}, \text { i.p) }+\mathrm{F} 3 \\
(500 \mathrm{mg} / \mathrm{kg} \text { in } 1 \% \text { Tween 80,p.o) }\end{array}$ & $\begin{array}{l}18.98 \pm 0.74 \\
\text { bns }\end{array}$ & $46.20 \pm 1.55^{\mathrm{b} * *}$ & $40.30 \pm 1.45^{\mathrm{b} * *}$ & $35.78 \pm 1.23^{\mathrm{b} * * *}$ & $\begin{array}{l}32.22 \pm 1.33 \\
\mathrm{~b}^{* * * *}\end{array}$ \\
\hline V & $\begin{array}{l}\text { (Streptozotocin } 60 \mathrm{mg} / \mathrm{kg} \text {, i.p) }+\mathrm{F} 5 \\
(250 \mathrm{mg} / \mathrm{kg} \text { in } 1 \% \text { Tween 80,p.o) }\end{array}$ & $\begin{array}{l}21.10 \pm 0.54 \\
\text { bns }\end{array}$ & $48.32 \pm 1.63^{\mathrm{b}^{* * *}}$ & $\begin{array}{l}42.62 \pm 1.69 \\
\mathrm{~b}^{* * * *}\end{array}$ & $37.56 \pm 1.22^{\mathrm{b}^{* * *}}$ & $\begin{array}{l}31.22 \pm 0.67 \\
\mathrm{~b}^{* * * *}\end{array}$ \\
\hline VI & $\begin{array}{l}\text { (Streptozotocin } 60 \mathrm{mg} / \mathrm{kg} \text {, i.p) }+\mathrm{F5} \\
(500 \mathrm{mg} / \mathrm{kg} \text { in } 1 \% \text { Tween 80,p.o) }\end{array}$ & $\begin{array}{l}19.67 \pm 0.144 \\
\text { bns }\end{array}$ & $42.52 \pm 1.68^{b^{* *}}$ & $\begin{array}{l}34.52 \pm 1.42 \\
b^{* * * *}\end{array}$ & $32.32 \pm 1.50^{\mathrm{b} * * *}$ & $25.32 \pm 0.78^{\mathrm{b} * * *}$ \\
\hline VII & $\begin{array}{l}\text { (Streptozotocin } 60 \mathrm{mg} / \mathrm{kg}, \text { i.p) }+ \text { Glipizide } \\
(5 \mathrm{mg} / \mathrm{kg} \text { in } 1 \% \text { Tween } 80, \mathrm{p} . \mathrm{o})\end{array}$ & $20.15 \pm 0.83^{\text {bns }}$ & $52.45 \pm 1.56^{\mathrm{b}^{*}}$ & $\begin{array}{l}35.30 \pm 1.65 \\
b^{* * *}\end{array}$ & $33.33 \pm 1.32^{\mathrm{b}^{* * *}}$ & $28.52 \pm 0.68^{\mathrm{b}^{* * *}}$ \\
\hline
\end{tabular}

Values are in Mean \pm S.E.M $(\mathbf{n}=6),{ }^{\text {ns }}$-Non Significant, $* \mathbf{p}<0.05, * * p<0.01, * * * p<0.001{ }^{\text {a }}$ Control compared with Normal, ' All test groups compared with Control using One way ANOVA followed by Dunnet's “ $t$ " test.

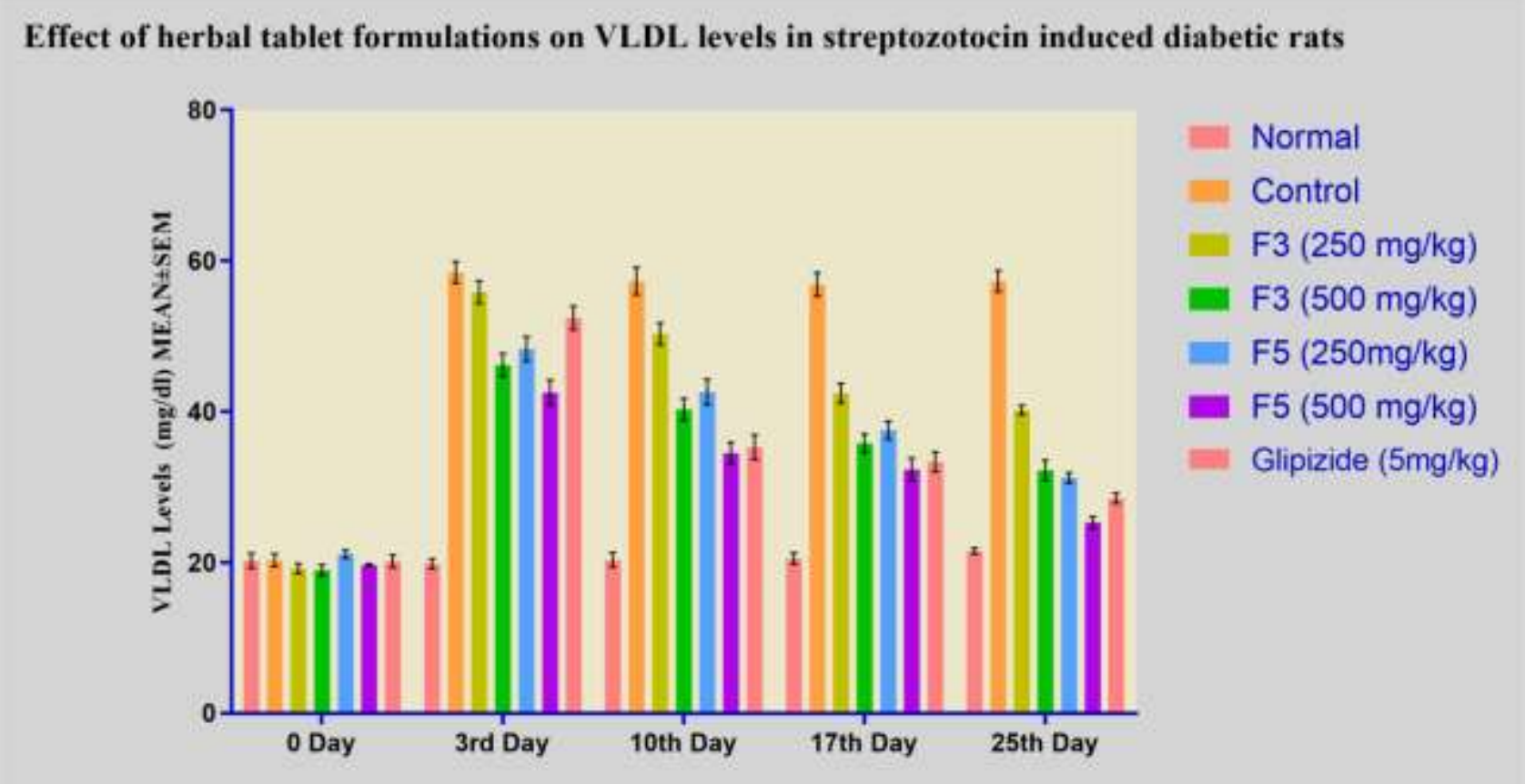

Figure-5: Effect of herbal tablet formulations on VLDL levels in streptozotocin induced diabetic rats 
Table-6: Effect of herbal tablet formulations on total cholesterol levels in streptozotocin induced diabetic rats

\begin{tabular}{|c|c|c|c|c|c|c|}
\hline \multirow[t]{2}{*}{ Groups } & \multirow[t]{2}{*}{ Treatment } & \multicolumn{5}{|c|}{ Total Cholesterol $(\mathrm{mg} / \mathrm{dl}) \mathrm{MEAN} \pm$ SEM } \\
\hline & & 0 Day & $3^{\text {rd }}$ Day & ${ }^{10 \text { th }}$ Day & $17^{\text {th }}$ Day & $25^{\text {th }}$ Day \\
\hline $\mathrm{I}$ & Normal (Vehicle1\% Tween 80,p.o) & $96.14 \pm 1.32$ & $95.17 \pm 1.60$ & $96.50 \pm 0.61$ & $97.20 \pm 0.67$ & $96.64 \pm 0.78$ \\
\hline II & $\begin{array}{l}\text { Control (Streptozotocin } 60 \text { mg/kg, i.p) } \\
+ \text { Vehicle1\% Tween 80,p.o) }\end{array}$ & $96.67 \pm 1.22^{\text {ans }}$ & $145.52 \pm 2.81^{\mathrm{a}^{* * * *}}$ & $137.22 \pm 2.17^{\mathrm{a}^{* * *}}$ & $137.20 \pm 2.50^{\mathrm{a}^{* * * *}}$ & $134.23 \pm 2.30^{\mathrm{a}^{* * * *}}$ \\
\hline III & $\begin{array}{l}\text { (Streptozotocin } 60 \mathrm{mg} / \mathrm{kg} \text {, i.p) + F3 } \\
(250 \mathrm{mg} / \mathrm{kg} \text { in } 1 \% \text { Tween } 80, \text { p.o })\end{array}$ & $95.68 \pm 1.44^{\text {bns }}$ & $122.32 \pm 1.62^{\text {bns }}$ & $124.82 \pm 2.45^{\mathrm{b}^{*}}$ & $118.32 \pm 1.20^{\mathrm{b}^{*}}$ & $114.50 \pm 1.65^{b^{*}}$ \\
\hline IV & $\begin{array}{l}\text { (Streptozotocin } 60 \mathrm{mg} / \mathrm{kg} \text {, i.p) }+\mathrm{F} 3 \\
(500 \mathrm{mg} / \mathrm{kg} \text { in } 1 \% \text { Tween } 80, \mathrm{p} .0)\end{array}$ & $97.12 \pm 1.54^{\text {bns }}$ & $114.32 \pm 1.62^{\mathrm{bns}}$ & $117.53 \pm 2.36^{\mathrm{b}^{* *}}$ & $97.52 \pm 1.72^{\mathrm{b}^{* * * *}}$ & $98.52 \pm 1.78^{\mathrm{b}^{* * *}}$ \\
\hline V & $\begin{array}{l}\text { (Streptozotocin } 60 \mathrm{mg} / \mathrm{kg} \text {, i.p) }+\mathrm{F} 5 \\
(250 \mathrm{mg} / \mathrm{kg} \text { in } 1 \% \text { Tween 80,p.o) }\end{array}$ & $95.50 \pm 1.56^{\text {bns }}$ & $120.08 \pm 1.65^{\mathrm{bns}}$ & $109.82 \pm 3.38^{\mathrm{b}^{* * *}}$ & $90.56 \pm 1.72^{\mathrm{b}^{* * *}}$ & $94.51 \pm 1.46^{\mathrm{b}^{* * * *}}$ \\
\hline VI & $\begin{array}{l}(\text { Streptozotocin } 60 \mathrm{mg} / \mathrm{kg}, \text { i.p) }+\mathrm{F} 5 \\
(500 \mathrm{mg} / \mathrm{kg} \text { in } 1 \% \text { Tween 80,p.o) }\end{array}$ & $95.66 \pm 1.78^{\mathrm{bns}}$ & $112.70 \pm 1.56^{\mathbf{b}^{*}}$ & $100.70 \pm 0.84^{\mathrm{b}^{* * *}}$ & $88.42 \pm 1.62^{\mathrm{b}^{* * * *}}$ & $84.60 \pm 1.08^{\mathrm{b***}}$ \\
\hline VII & $\begin{array}{l}\text { (Streptozotocin } 60 \mathrm{mg} / \mathrm{kg} \text {, i.p) } \\
\text { +Glipizide }(5 \mathrm{mg} / \mathrm{kg} \text { in } 1 \% \text { Tween } \\
\text { 80,p.o) }\end{array}$ & $96.30 \pm 1.90^{\text {bns }}$ & $130.54 \pm 1.45^{\text {bns }}$ & $110.35 \pm 2.97^{\mathrm{b} * * *}$ & $106.42 \pm 1.28^{\mathrm{b} * * *}$ & $107.30 \pm 1.45^{\mathrm{b} * *}$ \\
\hline
\end{tabular}

Values are in Mean \pm S.E.M $(\mathbf{n}=6)$, ${ }^{\mathrm{ns}}$-Non Significant, ${ }^{*} \mathbf{p}<0.05, * * \mathbf{p}<0.01, * * * \mathbf{p}<0.001{ }^{\text {a }}$ Control compared with Normal, ${ }^{b}$ All test groups compared with Control using One way ANOVA followed by Dunnet's “ $t$ " test.

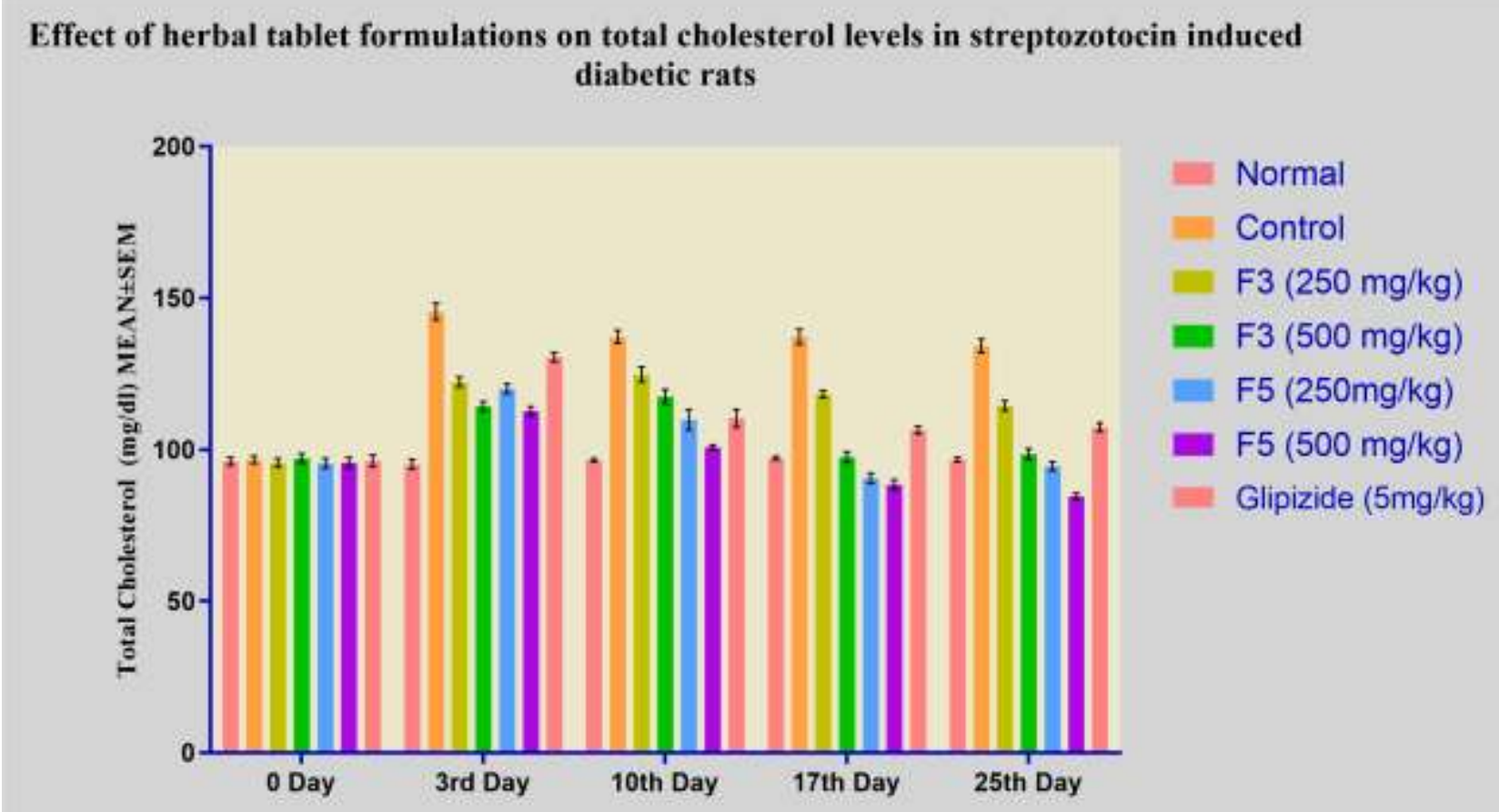

Figure-6: Effect of herbal tablet formulations on total cholesterol levels in streptozotocin induced diabetic rats 
Zaman AM \& Sharma HK; Saudi J Med Pharm Sci, September, 2020; 6(9): 627-638

Table-7: Effect of herbal tablet formulations on serum creatinine levels in streptozotocin induced diabetic rats

\begin{tabular}{|c|c|c|c|c|c|c|}
\hline \multirow[t]{2}{*}{ Groups } & \multirow[t]{2}{*}{ Treatment } & \multicolumn{5}{|c|}{ Creatinine LEVELS(mg/dl)MEAN \pm SEM } \\
\hline & & 0 Day & $3^{\text {rd }}$ Day & $10^{\text {th }}$ Day & $17^{\text {th }}$ Day & $25^{\text {th }}$ Day \\
\hline I & Normal (Vehicle1\% Tween 80,p.o) & $1.12 \pm 0.04$ & $1.13 \pm 0.04$ & $1.12 \pm 0.05$ & $1.15 \pm 0.04$ & $1.11 \pm 0.08$ \\
\hline II & $\begin{array}{l}\text { Control (Streptozotocin } 60 \text { mg/kg, } \\
\text { i.p) + Vehicle1\% Tween 80,p.o) }\end{array}$ & $1.08 \pm 0.04^{\mathrm{ans}}$ & $2.52 \pm 0.12^{\mathrm{a}^{* * * *}}$ & $2.48 \pm 0.06^{\mathrm{a}^{* * *}}$ & $2.48 \pm 0.06^{\mathrm{a}^{* * * *}}$ & $2.50 \pm 0.07^{\mathrm{a}^{* * * *}}$ \\
\hline III & $\begin{array}{l}\text { (Streptozotocin } 60 \mathrm{mg} / \mathrm{kg}, \text { i.p) }+\mathrm{F} 3 \\
(250 \mathrm{mg} / \mathrm{kg} \text { in } 1 \% \text { Tween } 80, \mathrm{p} . \mathrm{o})\end{array}$ & $1.06 \pm 0.05^{\mathrm{bns}}$ & $2.32 \pm 0.08^{\mathrm{bns}}$ & $1.76 \pm 0.08^{\mathrm{b}^{* *}}$ & $1.32 \pm 0.07^{\mathrm{b}^{* * *}}$ & $1.30 \pm 0.06^{\mathrm{b}^{* * *}}$ \\
\hline IV & $\begin{array}{l}(\text { Streptozotocin } 60 \mathrm{mg} / \mathrm{kg}, \mathrm{i} . \mathrm{p})+\mathrm{F} 3 \\
(500 \mathrm{mg} / \mathrm{kg} \text { in } 1 \% \text { Tween } 80, \mathrm{p} . \mathrm{o})\end{array}$ & $1.08 \pm 0.03^{\mathrm{bns}}$ & $2.22 \pm 0.08^{\text {bns }}$ & $1.56 \pm 0.05^{\mathrm{b**}}$ & $1.22 \pm 0.05^{\mathrm{b}^{* * *}}$ & $1.15 \pm 0.06^{\mathrm{b}^{* * *}}$ \\
\hline $\mathrm{V}$ & $\begin{array}{l}\text { (Streptozotocin } 60 \mathrm{mg} / \mathrm{kg} \text {, i.p) } \\
+\mathrm{F} 5(250 \mathrm{mg} / \mathrm{kg} \text { in } 1 \% \text { Tween } 80, \text { p.o })\end{array}$ & $1.13 \pm 0.03^{\text {bns }}$ & $2.28 \pm 0.07^{\mathrm{bns}}$ & $1.60 \pm 0.06^{\mathrm{b}^{* * * *}}$ & $1.28 \pm 0.06^{\mathrm{b}^{* * *}}$ & $1.17 \pm 0.05^{b^{* * * *}}$ \\
\hline VI & $\begin{array}{l}(\text { Streptozotocin } 60 \mathrm{mg} / \mathrm{kg}, \text { i.p) }+\mathrm{F} 5 \\
(500 \mathrm{mg} / \mathrm{kg} \text { in } 1 \% \text { Tween } 80, \mathrm{p} . \mathrm{o})\end{array}$ & $1.11 \pm 0.04^{\text {bns }}$ & $1.93 \pm 0.06^{\mathrm{b} * * *}$ & $1.52 \pm 0.07^{b^{* * * *}}$ & $1.12 \pm 0.08^{\mathrm{b}^{* * *}}$ & $1.12 \pm 0.07^{\mathrm{b}^{* * * *}}$ \\
\hline VII & $\begin{array}{l}\text { (Streptozotocin } 60 \mathrm{mg} / \mathrm{kg} \text {, i.p) } \\
\text { +Glipizide }(5 \mathrm{mg} / \mathrm{kg} \text { in } 1 \% \text { Tween } \\
80, \text { p.o) }\end{array}$ & $1.12 \pm 0.05^{\text {bns }}$ & $2.12 \pm 0.08^{\mathrm{b}^{* *}}$ & $1.70 \pm 0.06^{\mathrm{b}^{* * *}}$ & $1.13 \pm 0.04^{\mathrm{b}^{* * *}}$ & $1.18 \pm 0.08^{b^{* * * *}}$ \\
\hline
\end{tabular}

Values are in Mean \pm S.E.M $(n=6),{ }^{n s}$-Non Significant, ${ }^{*} \mathbf{p}<0.05, * * p<0.01, * * * p<0.001{ }^{\text {a }}$ Control compared with Normal, ' All test groups compared with Control using One way ANOVA followed by Dunnet's “ $t$ " test.

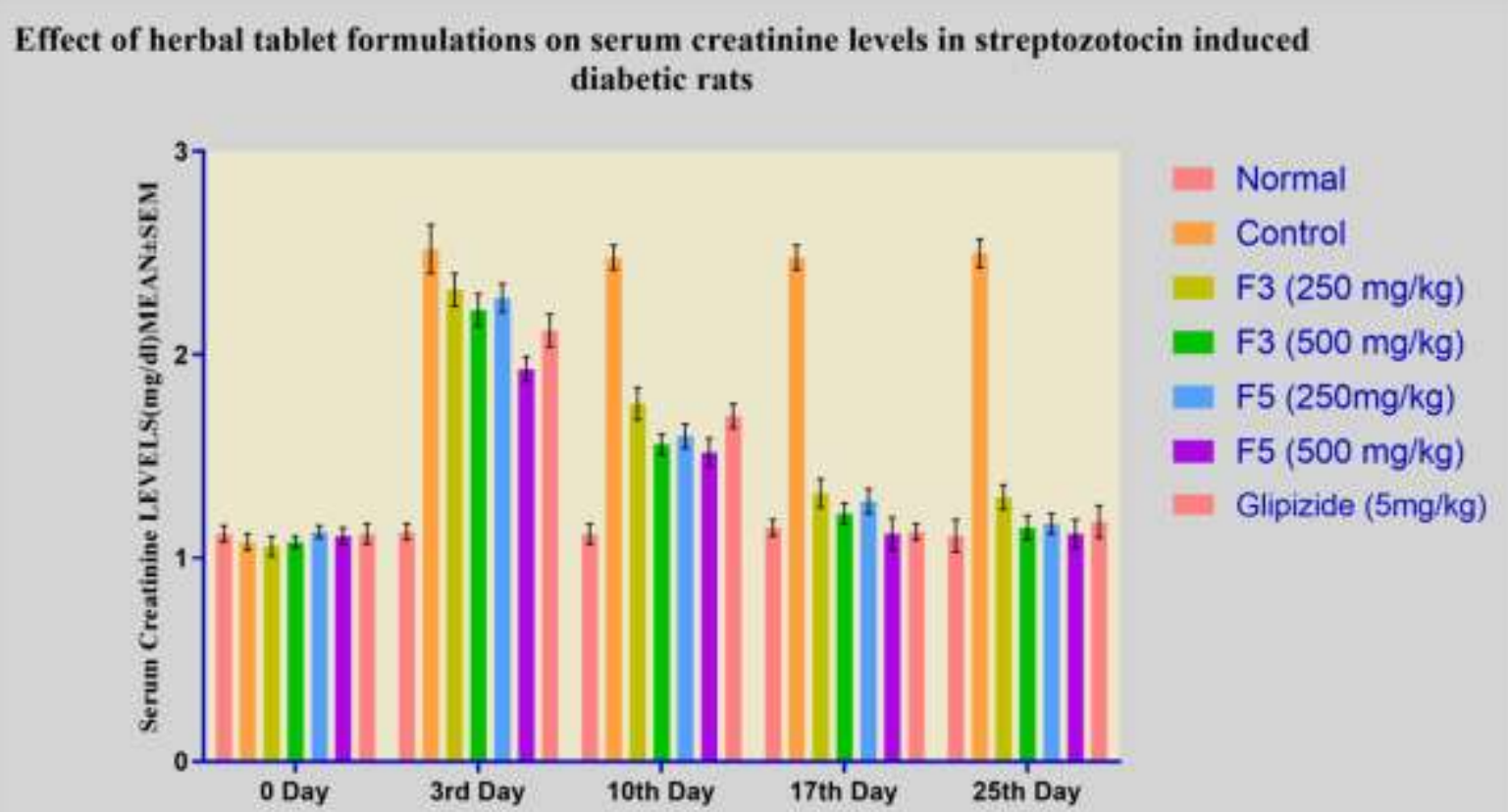

Figure-7: Effect of herbal tablet formulations on serum creatinine levels in streptozotocin induced diabetic rats 
Table-8: Effect of herbal tablet formulations on body weight in streptozotocin induced diabetic rats

\begin{tabular}{|c|c|c|c|c|c|c|}
\hline \multirow[t]{2}{*}{ Groups } & \multirow[t]{2}{*}{ Treatment } & \multicolumn{5}{|c|}{ Body weight ( gm). MEAN \pm SEM } \\
\hline & & 0 Day & $3^{\text {rd }}$ Day & ${ }^{10 \text { th }}$ Day & $17^{\text {th }}$ Day & $25^{\text {th }}$ Day \\
\hline $\mathrm{I}$ & $\begin{array}{l}\text { Normal (Vehicle1\% Tween } \\
\text { 80,p.o) }\end{array}$ & $157.28 \pm 3.43$ & $160.43 \pm 2.43$ & $167.50 \pm 1.58$ & $171.60 \pm 3.44$ & $173.30 \pm 4.50$ \\
\hline II & $\begin{array}{l}\text { Control (Streptozotocin } 60 \mathrm{mg} / \mathrm{kg} \text {, } \\
\text { i.p) + Vehicle1\% Tween 80,p.o) }\end{array}$ & $158.73 \pm 3.18^{\text {ans }}$ & $122.72 \pm 2.50^{\mathrm{a} * * *}$ & $\begin{array}{l}111.32 \pm 1.34 \\
a^{* * * *}\end{array}$ & $97.89 \pm 2.56^{\mathrm{a}^{* * * *}}$ & $90.86 \pm 2.55^{\mathrm{a}^{* * * *}}$ \\
\hline III & $\begin{array}{l}\text { (Streptozotocin } 60 \mathrm{mg} / \mathrm{kg}, \text { i.p })+ \\
\text { F3(250mg/kg in } 1 \% \text { Tween } \\
\text { 80,p.o })\end{array}$ & $\begin{array}{l}154.32 \pm 3.24 \\
\text { bns }\end{array}$ & $131.12 \pm 2.12^{\text {bns }}$ & $135.33 \pm 2.10^{\text {bns }}$ & $138.24 \pm 2.32^{b^{* * *}}$ & $143.40 \pm 2.20^{\mathrm{b}^{* * * *}}$ \\
\hline IV & $\begin{array}{l}\text { (Streptozotocin } 60 \mathrm{mg} / \mathrm{kg} \text {, i.p) + } \\
\text { F3(500mg/kg in } 1 \% \text { Tween } \\
\text { 80,p.o) }\end{array}$ & $\begin{array}{l}155.76 \pm 4.22 \\
\text { bns }\end{array}$ & $132.10 \pm 4.25^{\text {bns }}$ & $137.50 \pm 2.70^{b^{*}}$ & $144.44 \pm 2.40^{\mathrm{b}^{* * * *}}$ & $147.23 \pm 2.82^{b^{* * *}}$ \\
\hline $\mathrm{V}$ & $\begin{array}{l}\text { (Streptozotocin } 60 \mathrm{mg} / \mathrm{kg} \text {, i.p) } \\
+\mathrm{F} 5(250 \mathrm{mg} / \mathrm{kg} \text { in } 1 \% \text { Tween } \\
80, \text { p.o) }\end{array}$ & $\begin{array}{l}155.65 \pm 3.34 \\
\text { bns }\end{array}$ & $135.30 \pm 3.22^{\mathrm{b}^{*}}$ & $137.28 \pm 3.05^{\mathrm{b} * *}$ & $146.50 \pm 3.34^{\mathrm{b}^{* * * *}}$ & $151.65 \pm 3.66^{6 * * *}$ \\
\hline VI & $\begin{array}{l}\text { (Streptozotocin } 60 \mathrm{mg} / \mathrm{kg} \text {, i.p) } \\
+\mathrm{F} 5(500 \mathrm{mg} / \mathrm{kg} \text { in } 1 \% \text { Tween } \\
80, \text { p.o) }\end{array}$ & $\begin{array}{l}159.35 \pm 3.23 \\
\text { bns }\end{array}$ & $131.82 \pm 2.81^{\mathrm{bns}}$ & $138.33 \pm 2.50^{\mathrm{b} * * *}$ & $151.53 \pm 3.44^{\mathrm{b} * * *}$ & $156.24 \pm 2.86^{\mathrm{b} * * *}$ \\
\hline VII & $\begin{array}{l}\text { (Streptozotocin } 60 \mathrm{mg} / \mathrm{kg} \text {, i.p) } \\
\text { +Glipizide }(5 \mathrm{mg} / \mathrm{kg} \text { in } 1 \% \text { Tween } \\
\text { 80,p.o) }\end{array}$ & $\begin{array}{l}160.31 \pm 4.30 \\
\text { bns }\end{array}$ & $120.20 \pm 3.72^{\text {bns }}$ & $134.50 \pm 2.41^{\text {bns }}$ & $150.33 \pm 2.46^{\mathrm{b}^{* * * *}}$ & $152.34 \pm 1.76^{6 * * *}$ \\
\hline
\end{tabular}

Values are in Mean \pm S.E.M $(\mathrm{n}=6),{ }^{\text {ns }}$-Non Significant, $* \mathrm{p}<0.05, * * \mathrm{p}<0.01, * * * \mathrm{p}<0.001{ }^{\text {a }}$ Control compared with Normal, ${ }^{b}$ All test groups compared with Control using One way ANOVA followed by Dunnet's " $t$ " test.

Effect of herbal tablet formulations on body weight in streptozotocin induced diabetic rats

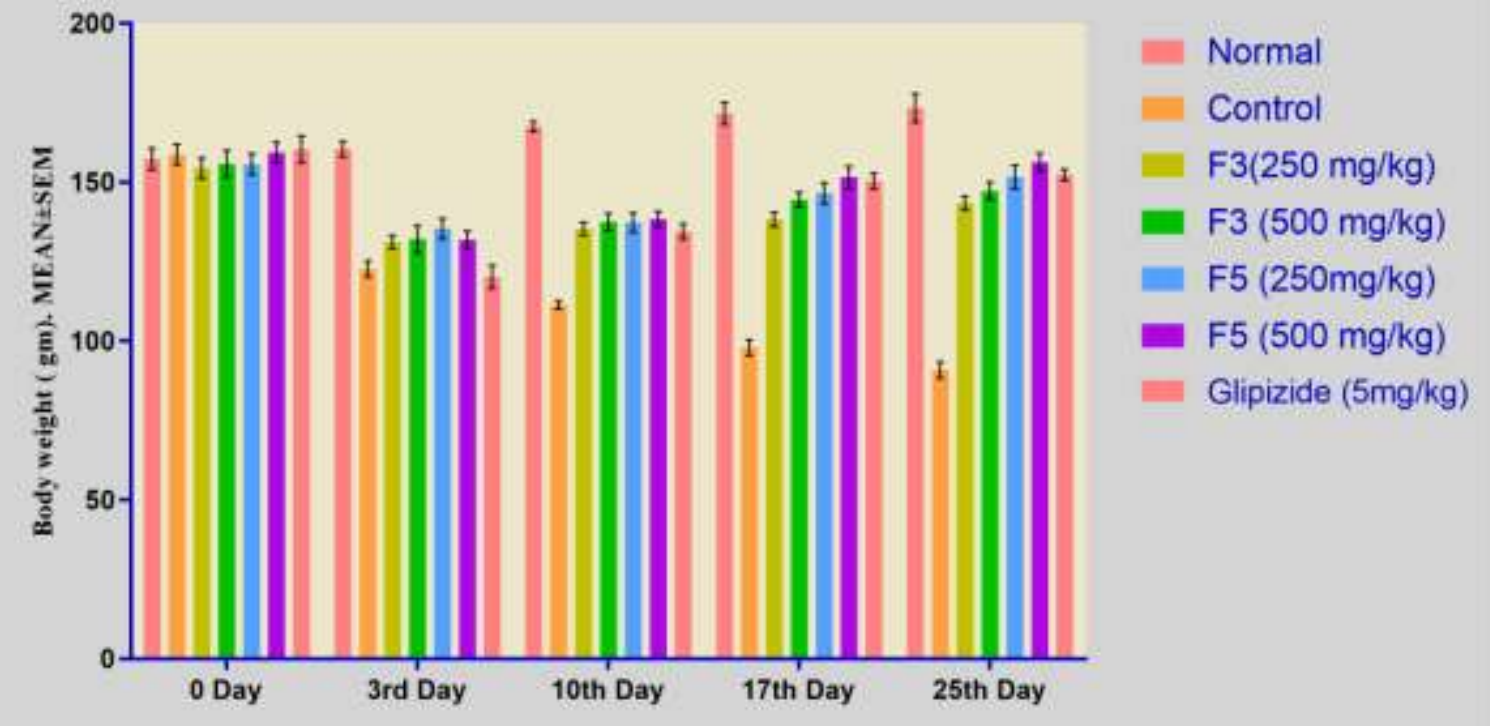

Figure- 8: Effect of herbal tablet formulations on body weight in streptozotocin induced diabetic rats 


\section{CONCLUSION}

Ant diabetic study of the herbal tablet were done in streptozotocin induced diabetic rats model and found significantly improve the various profiles like fasting on Blood glucose levels, Triglycerides levels, HDL levels and other biochemical parameters.

\section{REFERENCES}

1. https://environmentandforest.assam.gov.in/portlets/ biodiversity-of-assam- 0

2. Global report on diabetes (2016). World Health Organization, Geneva.

3. Gale, Jason (November 7, 2010). "India's Diabetes Epidemic Cuts Down Millions Who Escape Poverty". Bloomberg. Retrieved 8 June 2012.

4. "Diabetes can be controlled in 80 percent of Cases in India". IANS. news.biharprabha.com.

5. What is the cost of diabetes care? https://timesofindia.indiatimes.com/lifestyle/health-fitness/health-news/What-is-the-costof-diabetes-care/articleshow/49843288.cms

6. Yesudian, C. A., Grepstad, M., Visintin, E., \& Ferrario, A. (2014). The economic burden of diabetes in India: a review of the literature. Globalization and health, 10(1), 80.

7. Zaman, M.M., \& Sharma, D.H. (2020). Formulation and Evaluation of a poly herbal antidiabetic tablet containing Oryza sativa var. Joha Rice, Dillenia indica L and Syzygium cumini L extracts. Scholars Academic Journal of Pharmacy, 8(12), 547-551.

8. Rajasekaran, S., Sivagnanam, K., \& Subramanian, S. (2005). Antioxidant effect of Aloe vera gel extract in streptozotocin-induced diabetes in rats. Pharmacol Rep, 57(1), 90-6.

9. Kamtchouing, P., Sokeng, S. D., Moundipa, P. F., Watcho, P., Jatsa, H. B., \& Lontsi, D. (1998). Protective role of Anacardium occidentale extract against streptozotocin-induced diabetes in rats. Journal of ethnopharmacology, 62(2), 95-99.

10. Lenzen, S. (2008). The mechanisms of alloxan-and streptozotocin-induced diabetes. Diabetologia, 51(2), 216-226.

11. Sachdewa, A., \& Khemani, L. D. (2003). Effect of Hibiscus rosa sinensis Linn. ethanol flower extract on blood glucose and lipid profile in streptozotocin induced diabetes in rats. Journal of Ethnopharmacology, 89(1), 61-66.

12. Mabley, J. G., Southan, G. J., Salzman, A. L., \& Szabó, C. (2004). The combined inducible nitric oxide synthase inhibitor and free radical scavenger guanidinoethyldisulfide prevents multiple low-dose streptozotocin-induced diabetes in vivo and interleukin-1 $\beta$-induced suppression of islet insulin secretion in vitro. Pancreas, 28(2), e39-e44.

13. Wisetmuen, E., Pannangpetch, P., Kongyingyoes, B., Kukongviriyapan, U., Yutanawiboonchai, W., \& Itharat, A. (2013). Insulin secretion enhancing activity of roselle calyx extract in normal and streptozotocin-induced diabetic rats. Pharmacognosy research, 5(2), 65. 